\title{
ANCESTRALIDADE E INUTILIDADE NA OBRA POÉTICA DE MANOEL DE BARROS
}

\author{
Maria Fernanda Silva de Carvalho ${ }^{94}$
}

Resumo: Este artigo propõe discutir as relações entre ancestralidade e inutilidade na obra poética de Manoel de Barros, com base nas considerações do antropólogo brasileiro Eduardo Viveiros de Castro e dos pensadores alemães Theodor Adorno e Walter Benjamin, abordando a importância da ascendência indígena para o homem e para o poeta Manoel de Barros.

Palavras-chave: Manoel de Barros; Poesia; Ancestralidade; Inutilidade.

Abstract: This article proposes to discuss the relations between ancestry and uselessness in the poetic work of Manoel de Barros, starting the considerations of the brazilian anthropologist Eduardo Viveiros de Castro and of the germany thinkers Theodor Adorno and Walter Benjamin, approaching the importance of the indigenous ancestry for the man and for the poet Manoel de Barros.

Keywords: Manoel de Barros; Poetry; Ancestry; Uselessness.

\section{Introdução}

Manoel Wenceslau Leite de Barros nasceu em Cuiabá (MT) no ano de 1916 e foi criado em Corumbá (MS). Apesar de ter vivido nos mais diversos lugares ao longo de sua juventude, foi nessa cidade interiorana do estado do Mato Grosso do Sul, na fazenda de sua família, onde passou toda a sua infância, que nasceu Manoel de Barros, o poeta. O objetivo do presente artigo é discutir a importância das origens do homem Manoel para o nascimento do poeta e para o seu fazer poético ao longo dos anos - ao qual se dedicou até o fim de sua vida, em 2014, ano em que veio a falecer no mesmo Pantanal de sua infância, na cidade de Campo Grande -, abordando a questão da valoração do inútil e do ínfimo, essencial e constantemente presente em sua obra.

94 Mestranda do Programa de Pós-graduação em Literatura da Universidade Federal de Santa Catarina - UFSC. 
Para isso, este artigo foi organizado em quatro seções: "O homem, o poeta e as suas origens", “Nós" versus os "Outros" ou "Nós" versus "Nós"?", "Poesia, linguagem e sociedade” e "Manoel de Barros e Walter Benjamin: algumas relações", respectivamente. A primeira seção aborda as origens do homem e do poeta, discutindo as relações entre a poesia de Manoel de Barros e a sua ascendência indígena. A segunda seção, por sua vez, analisa a relação entre "primitivo" e "civilizado" apresentada por Manoel em sua obra poética e em suas entrevistas, a partir das considerações do antropólogo brasileiro Eduardo Viveiros de Castro (2002). Já a terceira seção discute, com base na "Palestra sobre lírica e sociedade", de Theodor Adorno, a importância da sociedade para a linguagem e, especificamente, para a poesia de Manoel de Barros. Por fim, a quarta seção se divide em duas partes, ambas ancoradas em "Sobre o conceito de história", de Walter Benjamin: a primeira, "Lembrando-se dos esquecidos, resgatando outras histórias", propõe uma breve reflexão política sobre a obra de Manoel de Barros; e a segunda, "Progresso e Modernidade", discute as visões do escritor alemão e do poeta brasileiro a respeito dos dois conceitos em questão.

\section{1. $\mathrm{O}$ homem, o poeta e as suas origens}

Segundo Manoel de Barros, ele nasceu "com o olhar para baixo" (BARROS, 2010a, p. 140), "para o ser menor, para o insignificante" (BARROS, 2013, p. 334), para aquilo que é considerado inútil e sem valor. O poeta não estava interessado nas coisas celestiais, mas naquelas que esfregam as suas barrigas no chão e que possuem "o privilégio de ouvir as fontes da Terra” (BARROS, 2010b, p. 31). Para ele, no ínfimo, há grandeza e exuberância. Com o seu olhar para baixo, Manoel entregou o ínfimo à poesia. A seu ver, apenas aquilo que é chão merece alcançar esse estágio.

"As correntes subterrâneas que atravessam o poeta transparecem no seu lirismo". A frase citada por ele em uma entrevista é de autoria de Theodor Adorno e nos revela o quão bem Manoel sabia da importância de suas raízes, de suas origens, para a sua poesia. "O que escrevo resulta de meus armazenamentos ancestrais e de meus envolvimentos com a vida." (BARROS, 2010a, p. 48), ele chegou a afirmar. $O$ poeta não se contentou apenas em falar "sempre com sotaque das suas origens" (BARROS, 2010b, p. 93), ele foi ainda "um caçador de achadouros de infância" (BARROS, 2010b, p. 67), catando os vestígios e juntando os fragmentos dela. Desse modo, tanto em entrevistas - a grande maioria por 
escrito, como preferia - como em poemas, Manoel de Barros relembrou a sua ascendência indígena, sempre associando uma de suas principais características a uma herança de seus antepassados: o olhar para baixo, torto.

"Pra ver o mundo com poesia boto meu olho torto" (BARROS, 2010a, p. 105), afirmou o poeta. O mesmo olho torto responsável por fazê-lo enxergar "o valor das coisas desimportantes, das coisas gratuitas" (BARROS, 2010a, p. 43, p. 45) e as "grandezas do ínfimo”. Para Manoel, "a importância de uma coisa há que ser medida pelo encantamento que a coisa produza em nós. Assim um passarinho na mão de uma criança é mais importante para ela do que a Cordilheira dos Andes." (BARROS, 2010b, p. 109). A esse seu modo de enxergar o mundo, detendo-se a coisas e seres considerados menores e inúteis, Manoel de Barros atribuía uma herança indígena, o que denominou de "atavismo bugral" (BARROS, 2010a, p. 84), pois, segundo ele,

[o] índio, o bugre, vê o desimportante primeiro (até porque ele não sabe o que é importante). Vê o miúdo primeiro, vê o ínfimo primeiro. Não tem noção de grandezas. [...] Bugre não sabe a floresta; ele sabe a folha (BARROS, 2010a, p. 84).

Em entrevistas, Manoel de Barros apontou dois significados de cultura fundamentais para discutirmos a relação entre poesia e ancestralidade em sua obra: o primeiro, comum aos dicionários, considera cultura como sinônimo de erudição, instrução vasta e variada e, predominantemente, livresca; já o segundo considera cultura como o caminho ao qual o ser humano precisa percorrer para se conhecer e tem suas origens na filosofia grega antiga. É evidente a importância desses dois significados de cultura para o fazer poético de Manoel, sobretudo, amalgamados. Afinal, o poeta uniu seus "estudamentos", como chamava seus estudos formais, livrescos, de tradição ocidental, europeia, às suas raízes bugres, às quais atribuía a sua ligação com a natureza, o seu gosto pelo primitivo e a sua fascinação pelas línguas e mitologias indígenas.

Para Manoel de Barros, a originalidade de sua poesia devia-se aos seus delírios com as palavras, à sua linguagem entortada pelos seus olhos para baixo, a qual privilegiava a imaginação e a invenção.

Não creio que a originalidade de um texto venha do lugar onde o autor nasceu ou tenha vivido. A infância que passei 
no Pantanal deixou em mim um lastro. É claro. Sou um depósito daquelas coisinhas do meu quintal. E aquelas coisinhas do meu quintal misturavam-se ao mesmo tempo às outras coisinhas dos meus armazenamentos ancestrais. Minha poesia há de ser um pouco o resultado dessa mistura, e mais o instinto linguístico. E um certo gosto de mexer com as palavras que adquiri no colégio. Sempre acho que seja mais importante para um estilo o gene que gerou o poeta do que o quintal em que brincou. No caso da originalidade é ainda importante o gosto esquisito que tenho pelas doenças da linguagem antes que pela saúde dela. A minha originalidade há de ser fruto de um coito anormal com letras. Gosto mais das sintaxes de exceção, da fala dos tontos, dos erros anônimos, dos termos espúrios. Sou um sujeito inconfiável: tem hora leio avencas, tem hora Proust (BARROS, 2010a, p. 124-125).

A respeito da formação do estilo do poeta, Manoel de Barros afirmou:

Do meu estilo não posso fugir. Ele não é só uma elaboração verbal. É uma força que deságua. A gente aceita um vocábulo no texto não porque o procuramos, mas porque ele deságua das nossas ancestralidades. $\mathrm{O}$ trabalho do poeta é dar ressonância artística a esse material. [...] Estilo é estigma. É marca. Todo estilo contém as nossas ancestralidades. [...] Papel do poeta é o de obter uma linguagem que o complete. Esse objeto de linguagem que me completa há de ser meu estilo (BARROS, 2010a, p. 157).

Para ele, o estilo do escritor se deve não apenas à sua produção intelectual - a sua escrita, o seu trabalho com as palavras - como a algo muito anterior a ela: a ancestralidade. A qual, por sua vez, pode ser entendida como essa marca que o escritor carrega, mas que, sem ser completada pela linguagem, não pode formar o seu estilo.

Talvez por isso mesmo Manoel de Barros sempre tenha buscado (e alcançado) uma linguagem não de comunicação, mas de comunhão com as suas origens. Para ele, a palavra poética "nasce bem mais dos sentidos que da mente. É o ser primário em nós que precisa reter-se nela. 
Não é o ser intelectual, o ser estudado, o ser culto que se expressa em poesia, mas o índio nele" (BARROS, 2010a, p. 135). A linguagem que fascina Manoel é a linguagem que se deixa romper pela imaginação e pela invenção e que, apenas assim, é capaz de transformar o ínfimo em estágio de poesia.

O poema "Gramática do Povo Guató", do livro Memórias Inventadas - As Infâncias de Manoel de Barros (2008), ilustra muito bem a relação entre o primitivo e o erudito, o indígena e o europeu, bem como a sua linguagem de comunhão.

Rogaciano era índio guató. Mas eu o conhecia na condição de bugre. (Bugre é índio desaldeiado, pois não?) Ele andava nas ruas de Corumbá bêbedo e sujo de catar papel por um gole de pinga no bar de Nhana. De tarde esfarrapado e com fome se encostava à parede de casa. A mãe fez um prato de comida e eu levei para Rogaciano. Ficamos a conversar. Ele ria pelas gengivas e mandava pra dentro feijão com arroz. $\mathrm{O}$ bife escorregava de gordura pelos beiços desse bugre. Rogaciano limpava a gordura com as costas da mão. Uma hora me falou que não sabia nem ler nem escrever. Mas seu avô que era o Xamã daquele povo lhe ensinara a Gramática do Povo Guató. Era a Gramática mais pobre em extensão e mais rica em essência. Constava de uma só frase: Os verbos servem para emendar os nomes. E botava exemplos: Bentevi cuspiu no chão. $O$ verbo cuspir emendava $o$ bentevi com o chão. E mais: $\mathrm{O}$ cachorro comeu o osso. $\mathrm{O}$ verbo comer emendou o cachorro no osso. Foi o que me explicou Rogaciano sobre a Gramática do seu povo. Falou mais dois exemplos: Mariano perguntou: - Conhece fazer canoa pessoa? - Periga Albano fazer. Respondeu. Rogaciano, ele mesmo, não sabia nada, mas ensinava essa fala sem conectivos, sem bengala, sem adereços para a gurizada. Acho que eu gostasse de ouvir os nadas de Rogaciano não sabia. E aquele não saber me mandou de curioso para estudar linguística. Ao fim me pareceu tão sábio o Xamã dos Guatós quanto Sapir (BARROS, 2010b, p. 105).

O personagem Rogaciano é um índio desaldeiado e, portanto, uma espécie de andarilho, figura à qual Manoel de Barros dava grande 
importância, pois acreditava que esse, além de vaguear por caminhos, inventa caminhos, sobretudo de linguagem, o que lhe dá, segundo o poeta, "uma linguagem de chão" (BARROS, 2010b, p. 147).

Neste poema, novamente, o modo como as coisas costumam ser valoradas na e pela sociedade é rompido por Manoel de Barros, visto que, mais uma vez, a medida se dá pelo encantamento: para o eu-lírico, a gramática do povo Guató não é rica em extensão, mas em essência. Tal encantamento é tão grande que coloca a sabedoria do Xamã dos Guatós ao lado da sabedoria de Edward Sapir, antropólogo e linguista alemão do final do século XIX. Essas "duas sabedorias" apontam para os dois significados de cultura comentados por Manoel de Barros e discutidos aqui anteriormente.

O mesmo pode ser observado no poema "As lições de R.Q.":

Aprendi com Rômulo Quiroga (um pintor boliviano):/A expressão reta não sonha./Não use o traço acostumado./A força de um artista vem de suas derrotas./Só a alma atormentada pode trazer para a voz um formato de pássaro./Arte não tem pensa:/O olho vê, a lembrança revê, e a imaginação transvê./É preciso transver o mundo./Isto seja:/Deus deu a forma. Os artistas desformam./É preciso desformar o mundo./Tirar da natureza as naturalidades./Fazer cavalo verde, por exemplo./Fazer noiva camponesa voar - como em Chagall (BARROS, 2013, p. 323-324).

$\mathrm{Na}$ nota introdutória que escreveu para a quarta parte de o Livro sobre nada (1996), onde está presente “As lições de R.Q.”, o eu-lírico afirma ter conhecido Rômulo Quiroga na aldeia indígena boliviana de Chiquitos. Assim como Manoel de Barros, Quiroga apreciava as coisas e os seres menores e insignificantes, inventando as suas próprias tintas a partir de materiais até então inúteis para a pintura, como "seiva de casca de angico [...]; caldos de lagartas [...]; polpa de jatobá maduro” (BARROS, 2013, p. 323), de modo a alcançar as cores que desejava. A aproximação entre a arte de Quiroga e a arte de Chagall também foi medida pelo encantamento, uma vez que ambas possuíam características muito caras ao poeta mato-grossense: invenção, imaginação, sonho, de(s)formação. Assemelhando-se, assim, pelo olhar torto, enviesado, que não deseja a linha reta, mas a curva. No entanto, ao contrário de Chagall, Rômulo Quiroga é um personagem ficcional, uma criação poética, que compõe 
uma das tantas memórias inventadas de Manoel de Barros. Desse modo, enquanto Marc Chagall foi um consagrado pintor europeu, Rômulo Quiroga foi um pintor indígena boliviano não apenas desconhecido, como ficcional.

Nesta mesma aldeia, na Bolívia, próxima a Corumbá (MS), Manoel de Barros viveu em sua juventude. Através da convivência com os índios chiquitos, o poeta percebeu as semelhanças entre a infância das crianças indígenas e a sua própria infância, sobretudo em relação às brincadeiras.

Fui criado no chão. Chão mesmo, terreiro. No meio das lagartixas e das formigas. Brincava com osso de arara, canzil de carretas, penas de pássaros. [...] Quando jovem, fui até viver algum tempo com os índios chiquitos, na Bolívia. Bebia chicha com eles e me alimentava de bocaiuva com leite de cabra. Dormia entre pedras e lagartos. Reparei que os filhos dos índios brincavam, como eu, no terreiro, com osso de arara, sabugos e pedaços de pote (BARROS, 2010a, p. 161).

Em sua obra, Manoel de Barros utilizou a palavra chão com frequência, a qual não é gratuita, pois remete tanto àquilo que é considerado ordinário, insignificante, rasteiro, como às raízes, às origens. O chão de Manoel de Barros é o chão do Pantanal e, especificamente, o do seu quintal, onde fazia objetos inúteis de brinquedos, assim como as crianças indígenas da aldeia de Chiquitos. Lá, Manoel de Barros reconheceu o seu chão.

Um dos significados encontrados para o vocábulo "chão" no Grande Dicionário Houaiss online é "local de origem ou onde se vive; querência, terra natal" (HOUAISS, 2012). Esse local de origem não é apenas do homem, mas também do poeta, uma vez que o chão do Pantanal de Manoel é, sobretudo, um chão de palavras. "O Pantanal está nas palavras. Palavras têm sedimentos." (BARROS, 2010a, p. 71), afirmou ele. Assim como o seu Pantanal físico possui um período de fortes chuvas que inundam o Rio Paraguai e que, após meses, dá lugar à seca, revelando, assim, sedimentos até então submersos pelas águas, o Pantanal poético de Manoel de Barros possui palavras sedimentadas por suas origens. Palavras essas que, segundo ele, "têm boa cópia de lodo, usos do povo, cheiros da infância, permanências por antros, ancestralidades” (BARROS, 2010a, p. 71). 


\section{2. “Nós” versus os "Outros” ou "Nós” versus "Nós"?}

Segundo Eduardo Viveiros de Castro, em seu livro A inconstância da alma selvagem (2002), o núcleo das teorias do Grande Divisor da Antropologia é o pensamento que singulariza "o Ocidente moderno frente às demais sociedades humanas" (CASTRO, 2014, p. 213), o qual pode ser sintetizado da seguinte maneira: “Nós" versus os "Outros"” (CASTRO, 2014, p. 213). Tal pensamento traz uma série de dicotomias, as quais sempre contêm alguma referência ao par primitivo/civilizado, que, por sua vez, pode ser observado tanto na obra poética de Manoel de Barros como em entrevistas concedidas por ele.

A primeira seção deste artigo já permite que enumeremos algumas referências a esse par mencionadas pelo poeta, a seguir: cultura como caminho para o autoconhecimento versus cultura como erudição; "leitura" de avencas, planta delicada e comum a diversos continentes, versus leitura de Proust, considerado um dos principais escritores franceses; sabedoria linguística do Xamã dos Guatós versus sabedoria linguística do renomado alemão Edward Sapir; pintura do ficcional artista indígena boliviano Rômulo Quiroga versus pintura do famoso pintor de arte moderna Marc Chagall, nascido na Rússia e radicado na França.

Os diferentes lugares nos quais Manoel de Barros viveu também ilustram esse par: o poeta morou em aldeias indígenas na Bolívia e no Peru, bem como morou no europeizado Rio de Janeiro da década de 30, onde se formou em Direito, e em Nova Iorque, onde fez um curso de cinema ainda jovem, passando também períodos em Paris, Itália e Portugal.

No poema "Soberania", por fim, o par apresentado parece sintetizar os demais: imaginação e inocência versus erudição. Interessante salientar que, neste poema, é a própria figura do erudito - no caso, Albert Einstein - quem ensina ao eu-lírico o gosto pelas pequenas coisas:

Naquele dia, no meio do jantar, eu contei que tentara pegar na bunda do vento - mas o rabo do vento escorregava muito e eu não consegui pegar. Eu tinha sete anos. A mãe fez um sorriso carinhoso para mim e não disse nada. Meus irmãos deram gaitadas me gozando. O pai ficou preocupado e disse que eu tivera um vareio de imaginação. Mas que esse vareios acabariam com os estudos. E me 
Ancestralidade e inutilidade na obra poética de Manoel de Barros | 325

mandou estudar em livros. Eu vim. E logo li alguns tomos havidos na biblioteca do Colégio. E dei de estudar pra frente. Aprendi a teoria das ideias e da razão pura. Especulei filósofos e até cheguei aos eruditos. Aos homens de grande saber. Achei que os eruditos nas suas altas abstrações se esqueciam das coisas simples da terra. Foi aí que encontrei Einstein (ele mesmo - o Alberto Einstein). Que me ensinou esta frase: A imaginação é mais importante do que o saber. Fiquei alcandorado! E fiz uma brincadeira. Botei um pouco de inocência na erudição. Deu certo. Meu olho começou a ver de novo as pobres coisas do chão mijadas de orvalho. E vi as borboletas. E meditei sobre as borboletas. Vi que elas dominam o mais leve sem precisar de ter motor nenhum no corpo. (Essa engenharia de Deus!) E vi que elas podem pousar nas flores e nas pedras sem magoar as próprias asas. E vi que o homem não tem soberania nem pra ser um bentevi (BARROS, 2010b, p. 183).

No entanto, é importante percebermos que, para e em Manoel de Barros, o par primitivo/civilizado não é dicotômico como pode parecer à primeira vista. Afinal, para o poeta, primitivo e civilizado não são excludentes, mas se completam: "A mistura não empobrece" (BARROS, 2010a, p. 152), pelo contrário, é enriquecedora: sua poesia foi germinada por essa mistura. Portanto, podemos pensar que o par de Manoel é primitivo-civilizado - não com barra, mas com hífen - visto que relaciona esses dois conceitos íntima e essencialmente: Manoel é "Nós" - civilizado, erudito, branco, ocidental, europeu - e "Outros" - primitivo, indígena, não-ocidental, não-europeu - concomitantemente.

\section{Poesia, linguagem e sociedade}

Em sua "Palestra sobre lírica e sociedade" (1957), Theodor Adorno discute, como sugere o título da palestra, as relações entre lírica e sociedade, apontando para a importância dessa última para a poesia, a qual normalmente costuma ser associada, antes de mais nada, à subjetividade de seu autor. Tal ideia é desmitificada por Adorno em seu texto, que ressalta o papel da objetividade e da sociedade para a poesia. Segundo ele, 
em cada poema lírico devem ser encontrados, no medium do espírito subjetivo que se volta sobre si mesmo, os sedimentos da relação histórica do sujeito com a objetividade, do indivíduo com a sociedade. Esse processo de sedimentação será tanto mais perfeito quanto menos a composição lírica tematizar a relação entre o eu e a sociedade, quanto mais involuntariamente essa relação for cristalizada, a partir de si mesma, no poema (ADORNO, 2003, p. 72).

Para Adorno, esse processo é possível somente através da linguagem.

O meio para isso [...] é a linguagem. [...] Pois a própria linguagem é algo duplo. Através de suas configurações, a linguagem se molda inteiramente aos impulsos subjetivos: um pouco mais, e se poderia pensar que somente ela os faz amadurecer. Mas ela continua sendo, por outro lado, o meio dos conceitos, algo que estabelece uma inelutável referência ao universal e à sociedade. As mais altas composições líricas são, por isso, aquelas nas quais o sujeito, sem qualquer resíduo da mera matéria, soa na linguagem, até que a própria linguagem ganha voz. $\mathrm{O}$ autoesquecimento do sujeito, que se entrega à linguagem como a algo objetivo, é o mesmo que o caráter imediato e involuntário de sua expressão: assim a linguagem estabelece a mediação entre lírica e sociedade no que há de mais intrínseco (ADORNO, 2003, p. 74).

A seu modo, Manoel de Barros parece ter compartilhado a ideia de Adorno a respeito do autoesquecimento do sujeito, que o permitiu ser guiado à poesia - e não guiá-la - pela linguagem: "sou principalmente criado pelas palavras. Elas inventam a gente mais do que a gente a elas. Elas me ocorrem. [...] O livro está dentro da gente. Tenho a convicção de que a poesia começa no desconhecer, no subconsciente" (BARROS, 2010a, p. 138). Para Adorno (2003, p. 75), "[o] instante do autoesquecimento, no qual o sujeito submerge na linguagem, não consiste no sacrifício do sujeito ao Ser. Não é um instante de violência, nem sequer de violência contra o sujeito, mas um instante de reconciliação", uma vez que a objetividade linguística alcançada por ele se torna a sua própria voz 
e, portanto, também a sua subjetividade, o que só é possível quando a linguagem deixa de falar daquilo que lhe é alheio.

A linguagem de Manoel de Barros era a sua própria voz. Em sua poesia, nada lhe era alheio. Manoel sabia que tudo aquilo a que dava valor - sendo, por conseguinte, a matéria de sua poesia - era justamente "[t]udo aquilo que a nossa civilização rejeita, pisa e mija em cima" (BARROS, 2010a, p. 45). Para ele, "[e]ngrandecer as coisas menores através da linguagem é uma das funções da poesia” (BARROS, 2010a, p. 52), função essa que exerceu com maestria ao longo de sua vida.

Todas as coisas para mim são palavras assim como todos os atos, sentimentos, etc. Assim, a palavra porcaria, por exemplo, é de minha estima. Para mim ela não é porcaria mesmo, lavagem de porco ou diarreia. Porcaria é uma palavra que pode ser alargada para gente. Ela pode ser humanizada. Ela pode nomear um bêbado deitado na sarjeta. Aí, nesse contexto humano, a palavra é nobre. Porque eu acho mais nobre um ser porcaria do que um ser ilustríssimo (BARROS, 2010a, p. 169).

Humanizar as palavras, para Manoel, era uma forma de humanizar o mundo. Mundo esse não apenas de "seres ilustríssimos", mas também e sobretudo - de "seres porcarias", ignorados, rejeitados, desprezados. Dentre esses, podemos pensar nas figuras do andarilho e do indígena, personagens recorrentes em sua poesia e essenciais para ela. "Poeta é um sujeito que mexe com palavras” (BARROS, 2010a, p. 138). Manoel acreditava que suas palavras poderiam resgatar, de algum modo, as vozes daqueles que não possuíam a oportunidade de resgatá-las por si próprios.

Para Adorno, a própria subjetividade poética do sujeito lírico deve a sua existência ao privilégio.

[S]omente a pouquíssimos homens, devido às pressões da sobrevivência, foi dado apreender o universal no mergulho em si mesmos, ou foi permitido que se desenvolvessem como sujeitos autônomos, capazes de se expressar livremente. Os outros, contudo, aqueles que não apenas se encontram alienados, como se fossem objetos, diante do desconcertante sujeito poético, mas que também foram rebaixados literalmente à condição de objeto da história, têm tanto ou mais direito de tatear em busca da própria 
voz, na qual se enlaçam o sofrimento e o sonho (ADORNO, 2003, p. 76-77).

Esse pequeno grupo detentor de tal privilégio - ao qual Manoel de Barros pertence - confirma as relações entre sujeito e objetividade e indivíduo e sociedade, visto que evidencia que "o teor [Gehalt] de um poema não é a mera expressão de emoções e experiências individuais" (ADORNO, 2003, p. 66), sendo essencialmente social, de modo a tornálo universal.

A idiossincrasia do espírito lírico contra a prepotência das coisas é uma forma de reação à coisificação do mundo, à dominação das mercadorias sobre os homens, que se propagou desde o início da Era Moderna e que, desde a Revolução Industrial, desdobrou-se em forma dominante da vida (ADORNO, 2003, p. 69).

Através de sua obra poética, Manoel de Barros buscou não apenas descoisificar o mundo como também lhe apresentar uma nova vida às coisas e aos seres coisificados, colocando, em seus poemas, assim, "a voz da humanidade" (ADORNO, 2003, p. 67).

\section{Manoel de Barros e Walter Benjamin: algumas relações}

\subsection{Lembrando-se dos esquecidos, resgatando outras histórias}

Uma questão central que perpassa todo o pensamento e, consequentemente, a obra de Walter Benjamin, certamente, é o messianismo, o qual, por sua vez, está atrelado à sua noção de redenção. Em suas teses "Sobre o conceito da história" (1940), a redenção messiânica discutida por Benjamin pode ser "compreendida simultaneamente de maneira teológica e profana” (LÖWY, 2005, p. 51), uma vez que tal redenção só seria possível através da rememoração histórica dos oprimidos, dos vencidos, dos esquecidos na obscuridade da história, de modo a atribuir, assim, "uma qualidade teológica redentora à rememoração, a seu ver, capaz de "tornar inacabado" o sofrimento aparentemente definitivo das vítimas do passado" (LÖWY, 2005, p. 50). Para Benjamin, apenas a rememoração - do passado - não é suficiente para que a redenção - do presente - aconteça, pois essa, para ser 
revolucionária, necessita de ação.

O poder messiânico não é apenas contemplativo - "o olhar voltado para o passado”. É também ativo: a redenção é uma tarefa revolucionária que se realiza no presente. Não é apenas uma questão de memória mas [...] trata-se de ganhar a partida contra um adversário poderoso e perigoso. "Éramos esperados na terra" para salvar do esquecimento os vencidos, mas também para continuar e, se possível, concluir seu combate emancipador (LÖWY, 2005, p. 53).

O messianismo de Benjamin é profano, sobretudo, pelo fato de ele, acreditando na ausência de Deus, atribuir completamente a tarefa messiânica às gerações humanas: "[o] único messias possível é coletivo: é a própria humanidade, mais precisamente, [...] a humanidade oprimida" (LÖWY, 2005, p. 52). Por outro lado, é também teológico pelo fato de acreditar que essa era a missão dos seres humanos na terra, os quais devem se lembrar de tudo e de todos, sem exceções, pois só assim a libertação será possível.

Benjamin acreditava que, a partir dessa rememoração redentora, outros lados da história, ou melhor, outras histórias poderiam ser visibilizadas. Nos dias atuais, é evidente que a historiografia "progressista", a qual mostra uma sucessão de vitórias das classes dominantes e opressoras, ainda é reinante, escamoteando diversas outras histórias, as quais apresentam uma série de derrotas catastróficas das classes subalternas e oprimidas.

Contra esse historicismo reinante, Benjamin propunha "escovar a história a contrapelo”. Expressão essa que, segundo Michael Lövy (2005, p. 73), possui um "formidável alcance historiográfico e político [e] significa, então, em primeiro lugar, a recusa em se juntar, de uma maneira ou de outra, ao cortejo triunfal que continua, ainda hoje, a marchar sobre daqueles que jazem por terra”. A expressão, que possui um duplo sentido - histórico e político -, trata, sobretudo, "de ir contra a corrente da versão oficial da história, opondo-lhes a tradição dos oprimidos” (LÖWY, 2005, p. 74), buscando romper com o curso natural da história e do "progresso" e possibilitando a redenção/revolução, que, por sua vez, deve sempre continuar, visto que "[a]s lutas atuais colocam em questão as vitórias históricas dos opressores, porque minam a legitimidade do poder das classes dominantes, antigas e atuais” (LÖWY, 2005, p. 74). 
Em sua tese II, Benjamin questiona: "Não nos afaga, pois, levemente um sopro de ar que envolveu os que nos precederam? Não ressoa nas vozes a que damos ouvido um eco das que estão, agora, caladas?" (LÖWY, 2005, p. 48). Em uma entrevista, Manoel de Barros faz uma declaração que parece dialogar com tais questionamentos de Benjamin: "Penso que o poeta pode e deve ser político. Mas a sua poesia não. Poesia não aguenta ideias. Verso não precisa dar noção. Precisa iluminar o silêncio das coisas." (BARROS, 2010a, p. 79). Essas afirmações de Manoel de Barros são bastante coerentes com a sua poesia e com a sua postura como poeta perante o mundo, visto que seus poemas não são políticos no sentido tradicional da palavra, uma vez que não procuram instruir ou convencer o leitor com "ideias" ou "noções": Manoel apresenta seu engajamento à medida que, através de seus poemas, ilumina "o silêncio das coisas" (BARROS, 2010a, p. 79) e das pessoas, ressoando, na sua própria voz, ecos de diversas vozes caladas.

\subsection{Progresso e Modernidade}

Na tese IX, sobre o Anjo da História, talvez a mais conhecida e discutida tese de "Sobre o conceito de história", Benjamin compara o progresso a uma tempestade que impele o anjo "irresistivelmente para o futuro, para o qual dá as costas, enquanto o amontoado de escombros diante dele cresce até o céu" (LÖWY, 2005, p. 87), levando-o a repetir o passado - sem poder parar para ajudar suas vítimas - com "novas catástrofes, novas hecatombes, cada vez mais amplas e destruidoras" (LÖWY, 2005, p. 90). Benjamin percebeu que o progresso deixava (e continua deixando) as pessoas de lado, uma vez que ele caminha sozinho, por si só, ou seja, as pessoas não o acompanham, não progridem com ele. Isso porque esse progresso é simplesmente técnico, faltando, nele, uma dimensão humana. Em "Sobre o conceito de história", bem como em outros textos de Benjamin, é evidente, portanto, o caráter negativo que ele atribui ao progresso e, consequentemente, à Modernidade.

Manoel de Barros também pensou a Modernidade, embora que de modo bastante distinto e particular: valorizando a inutilidade, o poeta apresentou, com sua obra, uma faceta positiva da Modernidade, a qual, na esteira de Benjamin e de outros teóricos, foi e continua sendo muito discutida pelo seu caráter negativo. Para Manoel de Barros, "tudo o que o homem fabrica vira sucata: bicicleta, avião, automóvel” (BARROS, 2010, p. 71), enquanto que o que pertence à natureza, como "ave, árvore, rã, pedra" (BARROS, 2010, p. 71), jamais se sucateia. O que é da natureza é 
Ancestralidade e inutilidade na obra poética de Manoel de Barros | 331

originalmente do chão e, portanto, matéria de poesia. Porém, o que é fabricado pelo homem, para se tornar natureza, ser chão e, finalmente, alcançar o estágio de poesia, precisa se tornar sucata. No poema "Latas", esse processo é explicado:

Estas latas têm que perder, por primeiro, todos os ranços (e artifícios) da indústria que as produziu. Segundamente, elas têm que adoecer na terra. Adoecer de ferrugem e casca. Finalmente, só depois de trinta e quatro anos elas merecerão de ser chão. Esse desmanche em natureza é doloroso e necessário se elas quiserem fazer parte da sociedade dos vermes. Depois desse desmanche em natureza, as latas podem até namorar com as borboletas (BARROS, 2010, p. 63).

Em seu livro Os Cinco Paradoxos da Modernidade (1990), Antoine Compagnon, referindo-se a Baudelaire, afirma que "os traços essenciais e paradoxais da tradição moderna [...], aos olhos do poeta, resultam de uma modernização do mundo, assimilada por ele a uma decadência; isto é, a um progresso rumo ao fim do mundo" (COMPAGNON, 1999, p. 30). Reconhecendo esse caráter "caótico" da Modernidade - capaz de transformar progresso em decadência -, Manoel de Barros mostra em sua poesia que é apenas na efemeridade da vida moderna que aquilo que o homem fabrica pode se tornar sucata tão rapidamente, de modo a perder a sua função, o que, para ele, é muito positivo. Afinal, somente assim, pode-se alcançar o estágio de poesia.

Ainda sobre a Modernidade, Benjamin escreveu em seu texto "Experiência e pobreza" (1933):

Pobreza de experiência: isso não deve ser compreendido como se os homens aspirassem a novas experiências. Não, eles aspiram a libertar-se de toda experiência, aspiram a um mundo em que possam ostentar tão pura e tão claramente sua pobreza, externa e também interna, que algo de decente possa resultar disso. Nem sempre, tampouco, são ignorantes ou inexperientes. Frequentemente pode-se afirmar o oposto: eles "devoraram" tudo, a "cultura" e o "ser humano", e ficaram saciados e exaustos. Ninguém mais do que eles sente-se atingido pelas palavras de Scheerbart: "Vocês estão todos tão cansados - e tudo porque não 
concentraram todos os seus pensamentos num plano totalmente simples mas absolutamente grandioso." (BENJAMIN, 2012, p. 127).

Concentrando não apenas seus pensamentos como também seus poemas "num plano totalmente simples" (BENJAMIN, 2012, p. 127), Manoel de Barros não se mostrou saciado nem exausto, mas sim capaz de perceber que, no abandono causado pela Modernidade, há espaço para a poesia.

\section{Considerações finais}

Vivendo a maior parte de sua vida no Pantanal de sua infância, Manoel de Barros foi um poeta pouco presente nos grandes centros urbanos e culturais do Brasil, como Rio de Janeiro e São Paulo, o que contribuiu para que se tornasse conhecido no meio cultural já na madureza, na década de 80 , mesmo tendo sido poeta desde jovem. Através de sua obra, podemos perceber que esse seu isolamento foi essencial para a sua poesia, pois o ligava às "fontes da Terra" (BARROS, 2010b, p. 31) e da sua terra. No seu chão, reconheceu seu olhar torto e para baixo como uma herança de sua ascendência indígena, enxergando nas coisas e nos seres inúteis e desimportantes o fundamento de sua poesia. E sua linguagem comungou com isso.

A linguagem de Manoel de Barros é a sua própria voz - a do poeta e a do homem que se denominava bugre e caipira - e, ainda, a voz de todos aqueles considerados os párias da(s) história(s) e da(s) sociedade(s): os vencidos e os esquecidos que a historiografia "progressista", discutida por Walter Benjamin, procura apagar, para que, assim, não possam ser lembrados nem salvos.

Ressaltando sempre sua mestiçagem - não apenas étnico-racial, como também cultural -, podemos dizer que Manoel de Barros, a seu modo, "escovou a história a contrapelo". Quando rememora a figura do indígena em sua obra, ele não aponta somente para a importância daquele para a sua formação como homem e como poeta, mas também, de maneira mais ampla, para a formação do Brasil, país no qual a população indígena foi e continua sendo dizimada pelo homem branco. Assim, Manoel de Barros contribuiu para "“tornar inacabado" o sofrimento aparentemente definitivo [dessas] vítimas do passado" (LÖWY, 2005, p. 50) e, infelizmente, ainda do presente. Afinal, como acreditava Walter Benjamin, a palavra também pode ser ação. 


\section{REFERÊNCIAS}

ADORNO, Theodor. Notas de literatura I. São Paulo: Editora 34, 2003.

BARROS, Manoel de. Manoel de Barros. Organização de Adalberto Müller. Rio de Janeiro: Beco do Azougue, 2010. (Coleção Encontros).

Memórias Inventadas: as infâncias de Manoel de Barros. São Paulo: Editora Planeta do Brasil, 2010. Poesia Completa. São Paulo: LeYa, 2013.

BENJAMIN, Walter. Magia e técnica, arte e política: ensaios sobre literatura e história da cultura. São Paulo: Brasiliense, 2012. (Obras Escolhidas v. 1).

CASTRO, Eduardo Viveiros de. A inconstância da alma selvagem. São Paulo: Cosac Naify, 2014.

COMPAGNON, Antoine. Os Cinco Paradoxos da Modernidade. Belo Horizonte: Editora UFMG, 1999.

HOUAISS, Antônio. Grande dicionário Houaiss. 2012. Disponível em: <https://houaiss.uol.com.br/>. Acesso em: 30 jan 2018.

LÖWY, Michael. Walter Benjamin: aviso de incêndio: uma leitura das teses "Sobre o conceito de história". São Paulo: Boitempo, 2005.

Recebido em: 11/02/2018

Aceito em: 14/03/2018 